\title{
Workplace-Based Assessment in Cross-Border Health Professional Education
}

Citation for published version (APA):

Wilbur, K., Driessen, E. W., Scheele, F., \& Teunissen, P. W. (2020). Workplace-Based Assessment in Cross-Border Health Professional Education. Teaching and Learning in Medicine, 32(1), 91-103. https://doi.org/10.1080/10401334.2019.1637742

Document status and date:

Published: 01/01/2020

DOI:

10.1080/10401334.2019.1637742

Document Version:

Publisher's PDF, also known as Version of record

Document license:

Taverne

Please check the document version of this publication:

- A submitted manuscript is the version of the article upon submission and before peer-review. There can be important differences between the submitted version and the official published version of record.

People interested in the research are advised to contact the author for the final version of the publication, or visit the DOI to the publisher's website.

- The final author version and the galley proof are versions of the publication after peer review.

- The final published version features the final layout of the paper including the volume, issue and page numbers.

Link to publication

\footnotetext{
General rights rights.

- You may freely distribute the URL identifying the publication in the public portal. please follow below link for the End User Agreement:

www.umlib.nl/taverne-license

Take down policy

If you believe that this document breaches copyright please contact us at:

repository@maastrichtuniversity.nl

providing details and we will investigate your claim.
}

Copyright and moral rights for the publications made accessible in the public portal are retained by the authors and/or other copyright owners and it is a condition of accessing publications that users recognise and abide by the legal requirements associated with these

- Users may download and print one copy of any publication from the public portal for the purpose of private study or research.

- You may not further distribute the material or use it for any profit-making activity or commercial gain

If the publication is distributed under the terms of Article $25 \mathrm{fa}$ of the Dutch Copyright Act, indicated by the "Taverne" license above, 


\title{
Workplace-Based Assessment in Cross-Border Health Professional Education
}

\author{
Kerry Wilbur $^{\mathrm{a}}$ (D) Erik W. Driessen ${ }^{\mathrm{b}}$, Fedde Scheele ${ }^{\mathrm{b}, \mathrm{c}}$ (D), and Pim W. Teunissen ${ }^{\mathrm{b}, \mathrm{d}}$ (D) \\ ${ }^{a}$ Faculty of Pharmaceutical Sciences, The University of British Columbia, Vancouver, British Columbia, Canada; ${ }^{b}$ School of Health \\ Professions Education (SHE), Department of Educational Research and Development, Maastricht University, Maastricht, The \\ Netherlands; 'Athena Institute, VU School of Medical Sciences, Amsterdam UMC, Amsterdam, The Netherlands; ${ }^{\mathrm{d} D e p a r t m e n t}$ of \\ Obstetrics \& Gynecology, VU University Medical Center, Amsterdam, The Netherlands
}

\begin{abstract}
Construct: The globalization of healthcare has been accentuated by the export of health professional curricula overseas. Yet intact translation of pedagogies and practices devised in one cultural setting may not be possible or necessarily appropriate for alternate environments. Purposeful examination of workplace learning is necessary to understand how the source or "home" program may need adapting in the distributed or "host" setting. Background: Strategies to optimize cross-border medical education partnerships have been largely focused on elements of campus-based learning. Determining how host clinical supervisors approach assessment in experiential settings within a different culture and uphold the standards of home programs is relevant given the influence of context on trainees' demonstrated competencies. In this mixed-methods study, we sought to explore assessor judgments of student workplace-based performance made by preceptors sharing a pharmacy curriculum in Canada and Qatar. Approach: Using modified Delphi consensus technique, we asked clinical supervisors in Canada $(n=18)$ and in Qatar $(n=14)$ to categorize trainee performance as described in 16 student vignettes. The proportion of ratings for three levels of expectation (exceeds, meets, or below) was calculated and within-country group consensus achieved if the level of agreement reached $80 \%$. Between-country group comparisons were measured using a chi-square statistic. We then conducted follow-up semi-structured interviews to gain further perspectives and clarify assessor rationale. Transcripts were analyzed using thematic content analysis. Results: The threshold for between-country group differences in assessor impressions was met for only two of the 16 student vignettes. Compared to Canadian clinical supervisors, relatively more preceptors in Qatar judged one described student as meets rather than exceeds expectations and one as meets rather than falls below expectations. Analysis of follow-up interviews exploring how culture may inform variations in assessor judgments identified themes associated with the profession, organization, learner, and supervisor performance theories but not their particular geographic context. Clinical supervisors in both countries were largely aligned in expectations of student knowledge, skills, and behaviors demonstrated in patient care and multidisciplinary team interactions. Conclusions: Our study demonstrated that variation in student assessment was more frequent among clinical supervisors within the same national context than any differences identified between the two countries. In these program settings, national sociocultural norms did not predict global assessor impressions or competency-specific judgments; instead, professional and organizational cultures were more likely to inform student characterizations of performance in workplace-based settings. Further study situated within the specific experiential learning contexts of cross-border health professional curricula is assuredly warranted.
\end{abstract}

\section{KEYWORDS}

cross-border medical

curriculum; clinical

supervisors; context; workplace-based assessment; pharmacy

\section{Introduction}

Globalization of health is advancing as patients, providers, and even diseases increasingly cross borders. ${ }^{1}$ Medical education has accentuated this internationalization of care as health professional curricula are exported overseas. ${ }^{2,3}$ Knowledge and skill transfer is in part accomplished when universities establish branch or satellite campuses hosted in foreign settings or, conversely, when domestic institutions adopt international programs or curricula. These particular

CONTACT Kerry Wilbur kerry.wilbur@ubc.ca Eaculty of Pharmaceutical Sciences, The University of British Columbia, 2405 Wesbrook Avenue, Vancouver, BC V6T 1Z3, Canada. (9@kerrywilbur; @UBCpharmacy 
cross-border education models have typically mobilized curricula from Western sources to other regions, but this orientation is diversifying. ${ }^{4,5}$ Benefits of these academic relationships include the provision of highcaliber content and training to place-bound students who will join the workforce within host countries as well as the extension of a home institution's expertise and global identity.

Yet intact translation of pedagogies devised in one cultural setting may not be possible or necessarily appropriate for alternate environments. ${ }^{6-9}$ Disparate learner attributes have been shown to influence adoption of necessary communication, group work, and self-directed study behaviors. ${ }^{10-13}$ Local Instructors have generally had no input into the source curriculum and may face challenges acclimatizing to, for instance, student-centered didactic approaches. ${ }^{13,14}$ Recommendations to mitigate host faculty and student "culture shock" are increasingly informed by various international program experiences within campusbased learning spaces, but how clinical supervisors and trainees approach teaching and assessment in workplace-based settings is less well anticipated and described.

The mini-CEX assessment strategy has been embraced internationally but has thus far been subjected to minimal prospective scrutiny for relevance prior to use in non-Western settings. ${ }^{15}$ The underlying premise of the mini-CEX is clinician provision of formative feedback based on observed trainee engagement in a patient encounter. ${ }^{16}$ However, cross-discipline studies demonstrate different cultural norms and preferences in feedback processes that may belie the fundamental aspects of this assessment method. Studies have found that medical students and residents in Indonesia and Thailand place greatest value on the feedback from specialist physicians and clinical faculty emphasize feedback for corrective measures. ${ }^{17,18}$ Little has been reported on how such distinct culturally influenced preferences impact other aspects of workplace-based learning and assessment.

In the experiential training component of exported curricula, concerns may arise regarding divergence in local clinical supervisors' teaching and assessment of trainees and ability to conform to intended standards. ${ }^{4,19}$ These supporting faculty members have usually qualified in different academic settings and have not previously mentored students within the hosts educational model. ${ }^{6,20,21}$ As such, these partners are asked to participate in processes with which they are less familiar or may have difficulty adopting. It may be foreseeable, then, that culture influences how clinical faculty supervise students and conduct workplace-based assessment. Although disparate aspects of rater judgment are increasingly acknowledged, existing studies of how clinical supervisors form impressions and make, express, and interpret trainee performance is predominantly derived from Western settings. ${ }^{22-24}$ Gaining greater understanding of assessment decisionmaking of clinical supervisors among different cultural contexts is particularly relevant for programs delivering cross-border curricula whereby academic partners strive to maintain source standards and align with local outlooks.

In the present study, we used a comparative education approach to explore assessor judgments of student performance during the experiential training component of a shared cross-border curriculum. ${ }^{25}$ The clinical supervision of workplace-based learning in such international education models is usually locally situated in geographically and often culturally distinct regions. Members of a culture are considered to possess to some extent a collective identity; common history and experience; and shared beliefs, values, and norms. ${ }^{26}$ Sociocultural theory in part assumes the perspective that context, including environmental, social, and cultural cues, shapes the behaviors of its constituents. ${ }^{27}$

However, culture is not only bound by geographic perimeters. Distinctions may also exist within a profession in that self-concept and roles are constructed and evolve under local conditions. ${ }^{28}$ In turn, an organization's culture is in part perpetuated through formal and informal practices of such individuals. ${ }^{29}$ Clinical supervisors within various contexts may be expected to perceive trainee performance through pluralistic cultural perspectives yielding dissimilar assessment. The existence or potential relevance of discrepancies between host and home preceptor standards for learners in the clinical component of crossborder curricula is largely unknown. Using a culturalist framework, we therefore sought to determine assessor impressions of student workplace-based performance in two countries and explore culturally informed variations in assessor judgments.

\section{Methods}

\section{Study setting}

The Doctor of Pharmacy (PharmD) program is a postbaccalaureate degree supporting the training of graduate students to assume advanced pharmacy practice positions as integrated members of multidisciplinary teams delivering direct patient care. Two 
Canadian institutions offer this degree, as well as the College of Pharmacy at Qatar University in Doha, Qatar. Established in 2007, the Qatar University College of Pharmacy is not a satellite college of another affiliate university or "branch campus" as previously described, but its professional degrees are accredited by the Canadian Council of Accreditation of Pharmacy Programs. ${ }^{30}$ Therefore, the mobilized curriculum is devised to meet the educational outcomes associated with Canadian pharmacist competencies for practice: Care Provider, Communicator, Collaborator, Leader/Manager, Scholar, Health Advocate, and Professional roles. ${ }^{31}$ Campus-based courses are delivered by an international faculty recruited to the university. Like students enrolled in the accredited programs with Canadian Council of Accreditation of Pharmacy Programs in Canada, pharmacy students in Qatar complete a minimum of 40 weeks of experiential training over the course of their program to meet degree requirements. Since 2012, pharmacy students have joined local practice settings for required workplace-based learning under the supervision of predominantly Arab adjunct clinical faculty.

The cultural characterization of specific contexts has been heavily informed by Hofstede's theoretical framework for studying a nation's profile and making cross-cultural comparisons. ${ }^{32}$ According to this framework, effects of a society's culture on its members' values are outlined by six domains (power distance, individualism, uncertainty avoidance, masculinity, long-term orientation, and indulgence) and may be used to study contrasts between countries according to their relative distinctions. Arab and North American societies such as Qatar and Canada, respectively, are typically positioned at opposite ends of described spectrums in power distance (e.g., high vs. low acceptance of inequalities in authority), individualism (low vs. high emphasis on independence and achievement of personal goals), and uncertainty avoidance (high vs. low affinity for rigid infrastructure and rules). Originally developed through a survey of how workplace values within the computer industry were influenced by culture, Hofstede's cultural dimensions concept has been widely applied in other fields, including health-related research pertaining to patient behaviors, provider care, and medical education. ${ }^{33-36}$ Although these cultural dimensions are considered group-level constructs, the framework is useful to advance the understanding of how specific cultural orientations may shape workplace-based assessment.

\section{Study design and methodology}

To explore how clinical supervisors in Canada and Qatar characterize trainee performance, we used student descriptions in a format comparable to the clinical vignette, a short and purposefully written description of a person or a situation conceived to simulate a real-world scenario. ${ }^{37-39}$ For our study, we developed student vignettes according to our prior findings of clinical supervisors in Canada and the Middle East who gave personal accounts of students (nameless) they had supervised during the experiential training component of North American-accredited pharmacy programs. ${ }^{40}$ We devised 16 student vignettes to describe pharmacist trainees who fell below, met, or exceeded expectations according to the seven major categories of performance outlined in these interviews (Table 1). The descriptions were further framed for consideration as students who had completed two thirds of the training program. The student vignettes were reviewed for content and clarity by two pharmacy preceptors in Canada and two in Qatar (Supplemental Material 1).

Using these student vignettes, we employed a mixed-methods design incorporating Delphi consensus measurement (quantitative) and interview techniques (qualitative) to explore assessor impressions across cultural contexts. The Delphi process was used to first elicit the supervisor characterizations of student performance, followed by interviews to gain greater insight and understanding of assessor rationale for these judgements. Data were collected between November 2016 and May 2017. The study was approved by the Qatar University Institutional Review Board (QU-IRB 613-E/16).

\section{Quantitative data collection and analysis}

We first explored clinical supervisor judgments using modified Delphi technique, a method used to systematically determine how well experts agree on a particular issue or idea. ${ }^{41}$ Features of this structured survey process include participant anonymity, iterative and controlled feedback by a central facilitator, and aggregation of responses. We invited pharmacists who have served as a clinical supervisor to at least 6 pharmacy trainees in domestic or international Canadianaccredited programs to participate in this study. These pharmacists from across Canada $(n=18)$ and Qatar $(n=14)$ who supervise postbaccalaureate Doctor of Pharmacy trainees assessed these student vignettes, presented randomly through a web-based platform, and were asked to categorize the descriptions 
Table 1. Major categories of expected pharmacy student performance and behaviors in workplace-based settings.

\begin{tabular}{|c|c|}
\hline Major Category & Definition \\
\hline \multicolumn{2}{|l|}{ Knowledge } \\
\hline Knowledge Base & $\begin{array}{l}\text { Demonstrates ability to recall disease processes and therapeutic knowledge } \\
\text { (including but not limited to, treatment alternatives, doses, mechanisms of } \\
\text { action, anticipated side-effects) }\end{array}$ \\
\hline Knowledge Translation & $\begin{array}{l}\text { Applies information and knowledge to specific patient cases; retains learned } \\
\text { information from earlier in the rotation for future use in care }\end{array}$ \\
\hline \multicolumn{2}{|l|}{ Team Interaction } \\
\hline Integration & $\begin{array}{l}\text { Swiftly adapts to the care setting and work environment; exhibits good judgment } \\
\text { in timing recommendations and is accepted by the team }\end{array}$ \\
\hline Contribution & $\begin{array}{l}\text { Contributes to direct patient care, including evidence-based patient decision- } \\
\text { making discussions at bedside rounds; decisions are based on good judgment; } \\
\text { does not avoid responsibility for care }\end{array}$ \\
\hline \multicolumn{2}{|r|}{ 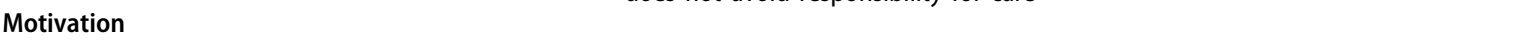 } \\
\hline Independence & $\begin{array}{l}\text { Proactively approaches work (patient care, assignments) with minimal prompting; } \\
\text { demonstrates advance and ongoing self-study/preparation; anticipates tasks and } \\
\text { often provides extra efforts in assigned tasks }\end{array}$ \\
\hline Disposition & $\begin{array}{l}\text { Exhibits enthusiasm, and curiosity in patient care and the learning process; } \\
\text { preceptor and team members enjoy working with and teaching them }\end{array}$ \\
\hline \multicolumn{2}{|r|}{ 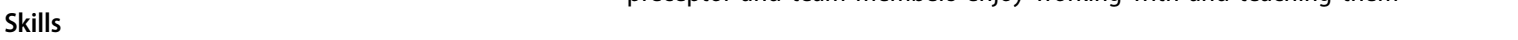 } \\
\hline Critical Thinking & $\begin{array}{l}\text { Demonstrates systematic process in patient-care and decision-making; can adapt } \\
\text { accordingly when new information is provided; judgments are appropriate } \\
\text { and safe }\end{array}$ \\
\hline Information Management & $\begin{array}{l}\text { Efficiently retrieves and accurately appraises literature associated with drug therapy } \\
\text { and patient management for their own learning and others' learning and } \\
\text { decision-making purposes }\end{array}$ \\
\hline Organization & Handles and prioritizes multiple tasks; punctual with assignments \\
\hline Patient Care & $\begin{array}{l}\text { Interacts comfortably with patients; caring attitude; seeks to inform and advocates } \\
\text { improved patient management }\end{array}$ \\
\hline \multicolumn{2}{|r|}{ 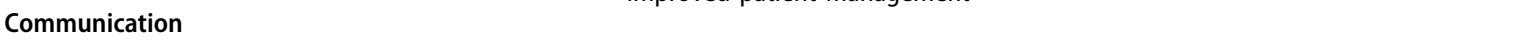 } \\
\hline Presentation/Written & $\begin{array}{l}\text { Creative and informative means to share information (presentation); clearly and } \\
\text { succinctly summarizes information (presentation/chart note/written assignments) }\end{array}$ \\
\hline Healthcare Members & $\begin{array}{l}\text { Can comfortably and appropriately engage in polite disagreements related to } \\
\text { patient-care and decision-making; shares information with preceptor and other } \\
\text { health professionals in clear and succinct fashion }\end{array}$ \\
\hline \multicolumn{2}{|r|}{ 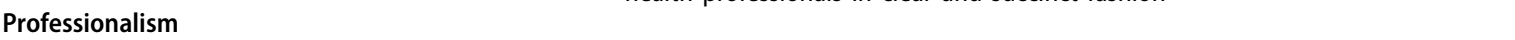 } \\
\hline Conduct & $\begin{array}{l}\text { Respects preceptor expertise and time; demonstrates commitment to the rotation } \\
\text { (arrives early and leaves late); appreciates learning opportunities }\end{array}$ \\
\hline Insight & $\begin{array}{l}\text { Reflects and responds to constructive feedback; never overconfident; recognizes } \\
\text { limitations }\end{array}$ \\
\hline
\end{tabular}

according to their perceptions of the outlined performances or behaviors: (a) exceeds, (b) meets, or (c) falling below their expectations. The process was conducted separately for supervisors in Canada and Qatar. In the subsequent Delphi round of review, aggregate results (by country) were shared with its contributors who could then alter their own initial choices.

The proportion of ratings for the three expectation categories for each description was calculated and collated for each country. Within-country group consensus of student vignette categorization was reached if the level of agreement among the participants was equal to or greater than $80 \%{ }^{42}$ Between-country group comparisons of student vignette characterization by clinical preceptors in Qatar and in Canada were made using chi-square statistic. The significance level was set at $5 \%$ and therefore the null hypothesis of no difference between-country groups would be rejected at $p$ values less than .05. Although we set quantitative thresholds for clinical supervisor agreement (within-country) and comparisons (betweencountry), we also used this method to scan for variability in collective judgments to guide selection of specific student vignettes suitable for qualitative analysis in the second part of our study.

\section{Qualitative data collection and analysis}

We next invited these supervisors from the two countries to participate in follow-up interviews to gain further perspectives and clarify the rationale for their characterizations of the student vignettes. To obtain maximum contrasts of views, we included participants of both genders representing a range of supervisory experience in both specialized and general, teaching and nonteaching patient care settings. Ten clinical supervisor interviews ( $n=5$ Qatar and $n=5$ Canada) were conducted by the first researcher $(\mathrm{KW})$ between 
March and May 2017 and lasted approximately one hour.

Based on outcomes of the Delphi rounds completed 2 to 10 weeks earlier, participants were presented with a collection of the 16 student narratives principally chosen according to between-country group differences and low levels of within-country group consensus. We asked participants to read each student vignette aloud and share any thoughts evoked by the given passage or section just spoken. If participants remained quiet after reading a section or conversely, completed several passages before pausing to verbalize their impressions, they were prompted by the researcher.

At the conclusion of each students' vignette reading, the researcher posed questions to gain further understanding of the participant's earlier statements. Discussions began iteratively, focusing on topics verbalized during participant reading of the student vignettes and then proceeded to specific questions structured to explore underlying cultural inferences or cues in these responses and informed in part by Hofstede's constructs of a society's cultural dimension. The interview guide was piloted with the same four pharmacists who reviewed and characterized the student vignettes, as described earlier (Supplemental Material 2). These individuals did not subsequently participate in the study.

All interview encounters were recorded and transcribed verbatim for analysis using thematic content analysis. ${ }^{43}$ Transcripts were read through several times and subjected to more detailed coding. Analysis began with open coding whereby the text was broken down by words or phrases into meaningful units. This initial coding was conducted with no sensitizing concepts apart from described content of the student narratives.

Using comparisons across transcripts, open codes were refined and combined into groups comprising potential major themes. The research team used a sample of three transcripts to generate an initial framework for thematic analysis. The coding scheme was further developed through additional open coding and constant comparison for fit or divergent cases. The first researcher (KW) then coded all data using the agreed-upon framework. She is a pharmacist familiar with experiential training in both settings having worked in both Canada and Qatar for nearly 10 years each. The balance of the research team (an educationalist active in education across different cultures [ED] and two physicians and medication education researchers in workplace-based learning [FS, PT]) provided additional outside perspectives. Coding and analysis was supported by qualitative data analysis software (QSR NVivo for MAC version 10).

\section{Results}

\section{Quantitative results}

Findings from the modified Delphi process to determine the level of agreement of trainee characterization between clinical supervisors in Canada and Qatar are presented in Table 2. Consensus judgments were obtained for 12 (Vignettes 1-4, 7-9, 11-14, 16) and seven students (Vignettes 2, 4, 7, 8, 11, 14, 16) among the Canadian and the Qatar preceptors, respectively. Although there was less within-country group agreement among the Middle East preceptors, the characterizations of several students matched those made by the Canadian clinical supervisors. For example, most clinical supervisors in Qatar also rated Vignettes 1 and 12 as meets expectations and Vignette 9 as exceeds expectations, but these proportions did not quite meet the $80 \%$ threshold for consensus. Both Canadian and Qatar preceptors were essentially split between meets and exceeds expectations for Vignettes 5 and 6. One third of Canadian and Qatar preceptors rated Vignette 10 as below expectations. Most clinical supervisors characterized Vignette 15 as exceeds expectations with fewer rating as meets; one Qatar preceptor rated this student as below expectations.

The threshold for between-country group differences in assessor impressions was met for two of the 16 student descriptions (Vignettes 3 and 13). When compared to preceptors in Canada, relatively more Qatar clinical supervisors judged the described student in Vignette 3 as meets rather than exceeds expectations and the student in Vignette 13 as meets rather than falls below expectations (Table 2).

Based on these results, student vignettes representing both discrepant and consensus trainee characterizations within and across the clinical supervisory groups were chosen for further review in participant interviews.

\section{Qualitative results}

Student descriptions in Vignettes 5, 6, and 15 were broadly blueprinted favorably across the seven major categories of workplace-based performance and behaviors (Table 1). When explored in follow-up interviews, features pushing judgments to "exceeds expectations" for Vignette 5 included his or her continuous progression built upon an apparent strong knowledge base 
Table 2. Clinical supervisor characterization of students described in vignettes.

\begin{tabular}{|c|c|c|c|c|c|c|c|c|c|}
\hline \multirow[b]{2}{*}{$\begin{array}{l}\text { Student } \\
\text { Vignette }\end{array}$} & \multicolumn{3}{|c|}{ Qatar Expectations } & \multirow[b]{2}{*}{$\begin{array}{c}\text { Level } \\
\text { of Agreement } \geq 80 \%\end{array}$} & \multicolumn{3}{|c|}{ Canada Expectations } & \multirow[b]{2}{*}{$\begin{array}{c}\text { Level } \\
\text { of Agreement } \geq 80 \%\end{array}$} & \multirow[b]{2}{*}{$\chi^{2} p$ value } \\
\hline & Below (\%) & Meets (\%) & Exceeds (\%) & & Below (\%) & Meets (\%) & Exceeds (\%) & & \\
\hline 1 & 14.3 & 78.6 & 7.1 & - & 11.7 & 82.4 & 5.9 & Yes & .943 \\
\hline 2 & 100 & 0 & 0 & Yes & 100 & 0 & 0 & Yes & - \\
\hline 3 & 13.3 & 40 & 46.7 & - & 0 & 5.9 & 94.1 & Yes & $.005^{*}$ \\
\hline 4 & 100 & 0 & 0 & Yes & 100 & 0 & 0 & Yes & - \\
\hline 5 & 0 & 40 & 60 & - & 0 & 47.1 & 52.9 & - & .581 \\
\hline 6 & 6.7 & 40 & 53.3 & - & 0 & 58.8 & 41.2 & - & .204 \\
\hline 7 & 93.3 & 0 & 6.7 & Yes & 100 & 0 & 0 & Yes & .249 \\
\hline 8 & 87.5 & 6.3 & 6.2 & Yes & 100 & 0 & 0 & Yes & .254 \\
\hline 9 & 0 & 37.5 & 62.5 & - & 0 & 11.7 & 88.3 & Yes & .467 \\
\hline 10 & 33.3 & 66.7 & 0 & - & 35.3 & 64.7 & 0 & - & .681 \\
\hline 11 & 13.3 & 86.7 & 0 & Yes & 17.6 & 82.4 & 0 & Yes & .854 \\
\hline 12 & 7.1 & 78.6 & 14.3 & - & 0 & 100 & 0 & Yes & .119 \\
\hline 13 & 66.7 & 33.3 & 0 & - & 100 & 0 & 0 & Yes & $.006 *$ \\
\hline 14 & 92.9 & 0 & 7.1 & Yes & 100 & 0 & 0 & Yes & .254 \\
\hline 15 & 7.1 & 21.4 & 71.5 & - & 0 & 23.5 & 76.5 & - & .514 \\
\hline 16 & 80 & 20 & 0 & Yes & 88.3 & 11.7 & 0 & Yes & .568 \\
\hline
\end{tabular}

Note. Student vignettes with $\geq 80 \%$ level of agreement denote a group consensus student characterization by clinical preceptors within the same country. Chi-square statistic compares the student vignette characterization by clinical preceptors in Qatar and in Canada.

${ }^{*} p<.05$ denotes a significant difference in student characterization by clinical preceptors between the two countries that is not attributed to chance alone.

(for preceptors in Canada) or his or her technologic acumen (for preceptors in Qatar). Raters from both countries who retained "meets expectations" for both Vignettes 5 and 6 did so because of a lack of a "wow factor" (QAT 2) or not going "above and beyond" (CAN 5). Preceptors also wanted more information about the complexity of the recommendations and care the student was providing. The difference between meeting and exceeding preceptor expectations for the student outlined in Vignette 15 was varied. This student was characterized as "doing everything the way we hope it would be done" by one Canadian preceptor assigning the performance as "exceeds," whereby a Qatar preceptor rating as "meets" also conceded the performance was as expected but not doing "something more."

All preceptors interviewed seemed to struggle judging the student described in Vignette 10, leading to discrepant judgments. The outlined unsatisfactory performance in knowledge application, independence, and critical-thinking skills were sufficient for preceptors in Qatar and Canada to rate "below expectations." However, some clinical supervisors in both countries teased out the positive aspects of this trainee's motivation toward care and attitude with regard to feedback. Given the student's point in the experiential training curriculum (one third remaining) coupled with a sense of responsibility to coach that the description seemed to evoke, some raters eventually settled upon meets expectation.

Like Vignettes 5, 6, and 15, Vignette 3 was also blueprinted favorably across the seven major categories of workplace-based performance and behaviors (Table 1). Nevertheless, unlike their Canadian counterparts, Qatar preceptors conservatively characterized as meets and (on occasion) below expectations. Some indicated doubt regarding the appropriateness of the independence demonstrated and wanted to know more about the student's application of primary literature to the care decisions described. Conversely, Vignette 13 outlined a student with practically global poor performance, yet some preceptors in Qatar allowed that the student seemed "hardworking" and "smart" but required confidence to unlock their true capabilities.

Data analysis of these interviews exploring how culture may inform variations in assessor judgments, and the sources for both within- and between-country groups, suggests that the societal norms typically associated with these two distinct geographic contexts do not play a big role. Instead, we identified themes of assessor influences associated with the (a) profession, (b) organization, (c) learner, and (d) supervisors themselves.

\section{Professional culture}

Clinical supervisors in Canada and Qatar expected pharmacist trainees to demonstrate the same fundamental professional skills and abilities. Examples frequently cited included interviewing patients to obtain medication histories or conducting medication counseling, interpreting laboratory and clinical data to assess safety and effectiveness of drug therapy, or critically appraising primary literature to deliver 
evidence-based care. Knowledge was valued but must be coupled with application under specific, and often changing, patient conditions.

So, they may say a better beta blocker is one of the three keys to heart failure management, but do they have the ability to provide nuance and is this for sure what's got to be done? In this patient this might be the exception. (CAN 5, Vignette 5)

The student is too rigid and too fixed in his or her mind and whatever they've learned or whatever they feel is appropriate is stuck in their head. (QAT 2, Vignette 13)

Trainees were expected to be proficient communicators. The ability to convey care was emphasized in that students must listen with empathy and address individual and family concerns and needs with respect.

It's a very important part as your job as a pharmacist-to listen-if you are looking the other way, the patient can take it like a sign of disrespect. (QAT 4, Vignette 1)

When they're trying to communicate with families, I would say they would minimally require preceptor guidance. (CAN 1, Vignette 1)

In Qatar, mixed-gender dynamics occasionally arise but do not appear to aversely influence care or the learning experience. For example, male trainees are expected to interact with female patients but must be mindful of their comfort or preference.

\section{Organizational culture}

Clinical supervisors in both countries expected pharmacist trainees to readily establish their role in the care environment. Students interact directly with patients but also collaborate with multidisciplinary colleagues to devise and execute care plans to achieve therapeutic goals. Mere physical presence during bedside rounds was insufficient; trainees characterized as meeting expectations contributed information when patient care discussions and decisions are taking place. Students should be capable to adapt their treatment plan when new data and perspectives emerge during these conversations. Supervisor concerns arose if treatment recommendations were not clearly communicated or supported by evidence.

We are part of the team, so we are not there for only observation. We have to share our opinion ... our experience, our knowledge. (QAT 3, Vignette 16)

If they're not providing recommendations and they're just agreeing with what the physician says when it's not the correct or maybe the best therapy, to me that's below expectations for our rotation in my unit. (CAN 4, Vignette 16)

Such patient care input carries the greatest weight if the trainee has formed positive working relationships with other care providers. All clinical supervisors highlighted the importance of "team fit"-what this means and how it arises. The recurring implication of cultivating a favorable team dynamic was the trainee's ability to mitigate and navigate disagreement with prescribers. Clinical supervisors wanted students to balance the confident pursuit of rational medication-related care decisions with collegial respect.

She needs to be able to be the patient's advocate and I think that should be her driving force-of not only just the physicians are right. (QAT 5, Vignette 13)

I don't see them advocating for the patient here, that they're reactive and what would concern me is ... if there were a critical medication-related problem I have no confidence that this pharmacist would act on it in order to achieve the patient's best outcome. (CAN 5, Vignette 13)

In this instance (Vignette 13), lack of patient advocacy contributed to unanimous below expectation rating by Canadian preceptors, unlike one third in Qatar who felt the student could still meet expectations.

Each clinical preceptor could describe hierarchal structures in their teams-"Yeah, there is a pecking order" (CAN 1). Although nonconfrontation and maintenance of group harmony are ideals typical to Qatar, clinical supervisors identified why trainees should not be dissuaded from expressing dissenting opinions.

Consultants and clinical pharmacists know that they can work together and when they disagree, that's fine and that's why we are here. We don't disagree to just fight; we are trying to improve patient care. (QAT 4, Vignette 9)

\section{Learner attributes}

Clinical supervisors in both countries considered generic student traits when rating trainee performance and behavior. Supervisors appreciated students who appeared open to receiving constructive feedback and used it to improve their performance. Other information useful for student characterization included demonstrated organizational skills. These were deemed essential to safe patient care, forecasted presumed trainee abilities once they reached the workforce, and in Qatar, was often associated with others' perception 
of the profession as a whole (not of the student alone).

The trainee's ability to manage multiple tasks and patient cases frequently factored into preceptor judgments. Clinical supervisors in Canada and Qatar rated below expectations students whom they could not trust to appropriately deliver unsupervised care.

... if they were not identifying all the relevant clinical data and modifying their daily plans, so sort of not really on top of things ... the preceptor couldn't be as confident and might have to start ... taking a second look at the patients. (CAN 3, Vignette 9)

He has daily progress notes, he reviews it regularly, he works independently ... so he took charge of the patient care and he understands that he is accountable for the patient. (QAT 4, Vignette 3)

However, the appropriateness of independent work was important. Across the different performance descriptions, preceptors in both countries outlined potential caveats ("Do they overrate their abilities?" CAN 2 or "[She's] ultimately under the responsibility of the preceptor" QAT 3) and uncertainty about such work outlined in Vignette 3 contributed to lower characterization of this student among a minority of Qatar raters.

In Qatar and Canada, clinical supervisors commended students who appeared committed to patient care and the learning experience but were also wary of the nature of this "extra work."

Showing that they are willing to go beyond what is actually required of them .... It shows that they are dedicated and doing it for their own interest as well. (QAT 2, Vignette 12)

I don't know ... when they stay too late in the evening, does that mean that they're not using their time effectively? (CAN 3, Vignette 13)

\section{Supervisory performance theories}

Pharmacists in Qatar and Canada revealed variable performance theories about trainee supervision, specifically for those students with perceived described deficiencies. Preceptors in both countries set clear thresholds for an overall student characterization of below expectations when certain competencies were not yet readily observed at the identified point in their training program. Meanwhile, other clinical supervisors offered "allowances" for initial poor performance when coupled with agreeable trainee behaviors (e.g., working hard, possessing a positive attitude, demonstrating progress) and judged them more leniently. Supervisors outlined coaching tactics they might implement for these trainees who were not meeting their expectations.

Transitioning from a student to a pharmacist you will have this confidence issue especially challenging people who have been in the field for many years and maybe specialists and whatever else ... maybe the preceptor could assist her with speaking up during the rounds and asking on every case "Do you have a comment?" ... I think she just needs a bit of a push on that. (QAT 2, Vignette 12)

Confidence seems to be the issue and they might need some role modeling; they might need a fair amount of support here. So I think this is a real opportunity to work with this individual. (CAN 5, Vignette 13)

\section{Discussion}

This study exploring cross-cultural differences in the workplace-based assessment of pharmacist trainees shows that clinical supervisors expect similar standards of performance and behaviors irrespective of the geographic context. We found high level of agreement between preceptor characterization of students described in the vignettes and largely concordant views on what shaped these impressions in the followup interviews. Discrepant assessor judgments anticipated by Qatar's and Canada's contrasting predominant societal norms and values were not borne out in our analysis. Middle East supervisors encouraged independence in patient care, discounted some elements of team harmony, and expected trainees to challenge physician authority when appropriate, which may be considered at odds with regional positions in dimensions of uncertainty avoidance, individualism, and power distance, respectively. The cultures influencing assessor judgments were instead more likely to be associated with the professional practices and organizational environments in which these students and preceptors are situated.

Student rating agreement between clinical supervisors in our study could be attributed in part to an unforeseen shared professional culture. Middle East pharmacy education programs are typically drug product oriented and reinforce the view of the pharmacist as a scientist. ${ }^{44}$ In North America however, pharmacists continue to assume expanded scopes of patient-centered practice, including independent prescribing authority. ${ }^{45}$ How is it, then, that these 
pharmacists' characterization of trainees in culturally distinct contexts is congruent?

Lave and Wenger previously described distributed communities of practice-groups not constrained by time or place. $^{46}$ Pharmacists recruited as clinical supervisors in Qatar are those who often engage with the profession internationally (e.g., conference attendance, society membership) and may have had additional advanced practice training from Western institutions themselves. The PharmD program at Qatar University has additionally invested in various preceptor development strategies and exposes practice-based faculty to curricular expectations through invited participation in campus-based student assessments. ${ }^{20,47,48}$ Unlike incomparable faculty knowledge and skills detected in other cross-border curricula, these clinical supervisors understand and accept the intended professional competencies taught in a Canadian-oriented program, and therefore their judgments of trainee performance may be uniquely aligned with North American counterparts. ${ }^{6}$

Curriculum equivalence of cross-border health professional education can be thwarted by gulfs between home and host healthcare systems and therefore the backdrop for workplace-based learning. ${ }^{6,13}$ If authentic experiences and interactions are necessary for optimal clinical learning, then training sites must facilitate inclusion. ${ }^{49,50}$ Like Canadian preceptors, Qatar clinical supervisors unfavorably characterized students who did not actively participate in therapeutic decisionmaking. Despite the lingering entrenched roles of physicians as the uncontested leads in Middle East patient care settings, these preceptors expect trainees to collaborate with multidisciplinary colleagues and respectfully debate inappropriate prescribing. However, such expectations are not necessarily typical for pharmacist trainees in the region. ${ }^{51}$ It would seem, then, that a local organizational culture exists where the legitimacy of pharmacists and trainees alike is recognized and disruptions to usual hierarchies is permitted.

How these conditions have developed in Qatar is unclear. However, the country is host to North American branch campuses training almost a dozen other health professionals (e.g., medicine, nursing, respiratory therapy), some of which have been in place for more than 15 years. ${ }^{52}$ It is possible that the confluence of students from these programs converging at these clinical teaching sites, and associated practice-faculty development, has in some way altered the culture of institutional healthcare training and customarily scripted disciplinary roles. Furthermore, the pharmacists in our study appear to have cultivated microenvironments of advanced practice, which they closely curate; participants from Qatar more often emphasized concern for how trainee performance and behavior would reflect upon the profession as a whole.

Ideally, clinical supervisors facilitate student learning by enabling patient care activities while recognizing and accommodating individual trainee needs and abilities. However, the supervisory efforts expended seem to have implications on the student impressions they form. Ginsburg et al. have previously described how medical residents who consume staff attention could be perceived as "problematic." 53 In Bogo's work with social work field supervisors, excessively needy students strained relationships. ${ }^{54}$ We did not set out to expressly study the clinical teaching attitudes or behaviors of our sample population, but evidence of "supervisory cultures" surfaced during participant interviews. In both Canada and Qatar, a number of preceptors expressed commitment to coach certain students who struggle to meet their expectations. However, the extent of such supervisory allowances was not uniform, as others were resolute in expectations of self-directed learning and independent work. Opportunity for trainees to function as independent clinicians is fundamental to the experiential element of health professional curricula. Qatar clinical supervisory preferences for student autonomy in a cultural setting where unstructured situations elicit discomfort and decision-making is often centralized are noteworthy.

Through our mixed-methods approach, we were able to corroborate results of assessor impressions in Canada and in Qatar. Quantitatively, we illustrated within-country group disagreement in student ratings among clinical supervisors before making comparisons between countries. Qualitatively, we used the student vignette approach employed by others exploring trainee characterization by clinical supervisors in social work and medicine. ${ }^{37,55}$ In this way, we further support our findings of cross-border consistency; preceptor judgments are also similar in how they are dissimilar. The bases of within-group differences were often shared by pharmacists in Canada and in Qatar and according to assessment phenomenon previously described. We too found how preceptors in both countries often agreed with one another about described or observed student performance and then made contrasting judgments according to their own benchmarks and priorities for a trainee's work and patient care. $^{22-24} \mathrm{We}$ are mindful that lack of the 
within-group consensus in our Delphi results obscured abilities to ascertain statistically significant differences in our between-country comparison. Nevertheless, in our in-depth qualitative analysis, we were still unable to uncover specific cultural influences on rater expectations as framed by Hofstede's theoretical theory.

The vignettes created for our study were informed by accounts of student performance and behaviors previously offered by clinical supervisors in Qatar and Canada. Although implicit messages are often embedded in such narratives' language, assessors are still able to consistently interpret descriptions and characterize students despite unfamiliarity with local contexts. ${ }^{56}$ However, this method could fall short as a suitable surrogate for impressions formed following actual direct observation of trainees. We intentionally used gender-neutral written descriptions to eliminate potential visual cues that could contribute to unconscious rater bias, and reassuringly, student vignettes did resonate with the participants. Clinical supervisors are nevertheless more accustomed to making judgments of trainees with whom they spend time. Although preceptors were comfortable arriving at the requested summative assessment, participants did on occasion in the interview component indicate a desire for information not described in the student vignette in order to arrive at a more fully informed assessment characterization.

Albeit the predominant cultural theory, Hofstede's framework is not without detractors. ${ }^{57}$ McSweeney has put forth one of the most compelling criticisms challenging the suitability of using individuals' survey responses to represent an entire nation's values and the reductionism of complex behaviors into five finite dimensions. ${ }^{58}$ Jones also invokes the dynamic influence of the prevailing political climate at the time of data collection (1960s). ${ }^{59}$ Irrespective of methods or era, most subsequent models of national culture have in fact arrived at comparable descriptive constructs to understand and contrast cultures, and Hofstede himself reemphasizes how the validity of his labeled dimensions have withstood repeated measurements over time across broad fields of study. ${ }^{60,61} \mathrm{We}$ are comfortable with the suitability of Hofstede's cultural dimensions as a means to explore assessor judgments in North American and Middle East contexts. The absence of discernable difference in student assessment by clinical supervisors in the two national settings that may have been anticipated according to this theory does not in and of itself further censure the framework. Indeed, we may have considered using
Hofstede's cultural dimensions to determine cultural orientations at the individual level as other researchers have done. ${ }^{33}$

As this study of workplace-based assessment was conducted in a cross-border pharmacy education program in Qatar, our findings may not be transferable. The pharmacist training program under comparison with Canada is not a typical cross-border partnership with a branded home campus satellite. We are unable to explicitly mark how ours and the other actual branch health professional programs positioned in this host country have affected the local health system or training over time. "Learner-friendly" clinical environments may have evolved, and therefore our findings are not necessarily reflective of clinical supervisor expectations in other Arab settings. Indeed, Hodges et al. have called for a broader examination of the impacts of cross-border medical education programing on local healthcare systems and care providers, but little work has yet been done in this regard. ${ }^{62}$ Researchers might consider the transferability of our results to the practice environment in other settings, within the Middle East or otherwise, taking into account their own health profession's cross-border curriculum and workplace-based context.

\section{Practical implications}

Continued growth of global partnerships in health professional education necessitates ongoing quality assurance. Although prior work has described crossborder curriculum implementation experiences, ours is the first study to examine workplace-based assessment of enrolled students training in domestic practice environments. In this particular geographic setting, the tensions inherent between local adaptation and preservation of program standards as it pertains to workplace-based assessment would appear to be reconciled. Specifically, national societal norms were not associated with global assessor impressions or competency-specific judgments; instead, professional and organizational cultures were more likely to inform student characterizations. Further study of the experiential curriculum in this and other cross-border medical education partnerships is assuredly warranted and should incorporate questions about other practical aspects of the workplace-based training, including student perspectives and how home programs influence host practice settings and the resultant institutional culture. 


\section{Acknowledgments}

We thank all participants of this study for their time and willingness to share their perspectives.

\section{Competing interest}

The authors report that they have no conflicts of interest to declare.

\section{ORCID}

Kerry Wilbur (D) http://orcid.org/0000-0002-5936-4429

Fedde Scheele (D) http://orcid.org/0000-0001-9593-257X

Pim W. Teunissen (D) http://orcid.org/0000-0002-0930-0048

\section{References}

1. Woodward D, Drager N, Beaglehole R, Lipson D. Globalization and health: a framework for analysis and action. Bull World Health Organ. 2001;79(9): 875-881.

2. Kosmutzky A, Putty R. Transcending borders and traversing boundaries: a systematic review of the literature on transnational, offshore, cross-border, and borderless higher education. J Stud Int Educ. 2016;20: 8-33. doi:10.1177/1028315315604719.

3. Altbach PG, Knight J. The internationalization of higher education: motivations and realities. J Stud Int Educ. 2007;11(3-4):290-305. doi:10.1177/ 1028315307303542 .

4. Zhang L, Kinser K, Shi Y. World economies and the distribution of international branch campuses. Int High Educ. 2014;7:8-9. doi:10.6017/ihe.2014.77.5674.

5. Kahn HE, Agnew M. Global learning through difference: considerations for teaching, learning, and the internationalization of higher education. J Stud Int Educ. 2017;21:52-64. doi:10.1177/1028315315622022.

6. Waterval DG, Frambach JM, Oudkerk Pool A, Driessen EW, Scherpbier AJ. An exploration of crossborder medical curriculum partnerships: balancing curriculum equivalence and local adaptation. Med Teach. 2015;38:255-262. doi:10.3109/0142159X.2015. 1019439.

7. Mackay M, Joyce-McCoach J, Stephens M, et al. Review of transnational nursing education programme curricula: process, findings, and recommendations. Nurse Educ Today. 2016;42:73-77. doi:10.1016/j.nedt. 2016.04.004.

8. Gosselin K, Norris JL, Ho MJ. Beyond homogenization discourse: reconsidering the cultural consequences of globalized medical education. Med Teach. 2016; 38(7):691-699. doi:10.3109/0142159X.2015.1105941.

9. Shams F, Huisman J. The role of institutional dual embeddedness in the strategic local adaptation of international branch campuses: evidence from Malaysia and Singapore. Stud High Educ. 2016;41(6): 955-970. doi:10.1080/03075079.2014.966669.
10. Gwee M-E. Globalization of problem-based learning (PBL): cross-cultural implications. Kaohsiung J Med Sci. 2008;24:S14-S22.

11. Frambach JM, Driessen EW, Chan LC, van der Vleuten C. Rethinking the globalisation of problembased learning: how culture challenges self-directed learning. Med Educ. 2012;46(8):738-747. doi:10.1111/j. 1365-2923.2012.04290.x.

12. Jippes M, Majoor GD. Influence of national culture on the adoption of integrated and problem-based curricula in Europe. Med Educ. 2008;42(3):279-285. doi: 10.1111/j.1365-2923.2007.02993.x.

13. Waterval DGJ, Frambach JM, Driessen EW, Scherpbier A. Copy but not paste: a literature review of crossborder curriculum partnerships. J Stud Int Educ. 2015;19(1):65-85. doi:10.1177/1028315314533608.

14. Waterval DG, Frambach JM, Driessen EW, Muijtjens A, Scherpbier AJ. Connected, attracted, and concerned: AQ study on medical crossborder curriculum partnerships. Med Teach. 2018;40(12):1293-1299.

15. Suhoyo Y, Schönrock-Adema J, Rahayu GR, Kuks JBM, Cohen-Schotanus J. Meeting international standards: a cultural approach in implementing the mini-CEX effectively in Indonesian clerkships. Med Teach. 2014;36(10):894-902. doi:10.3109/0142159X. 2014.917160.

16. Norcini JJ. The mini clinical evaluation exercise (mini-CEX). Clin Teach. 2005;2(1):25-30. doi:10.1111/ j.1743-498X.2005.00060.x.

17. Suhoyo Y, van Hell EA, Prihatiningsih TS, Kuks JBM, Cohen-Schotanus J. Exploring cultural differences in feedback processes and perceived instructiveness during clerkships: replicating a Dutch study in Indonesia. Med Teach. 2014;36(3):223-229. doi:10.3109/ 0142159X.2013.853117.

18. Wong AK. Culture in medical education: comparing a Thai and a Canadian residency programme. Med Educ. 2011;45(12):1209-1219. doi:10.1111/j.1365-2923. 2011.04059.x.

19. Segouin C, Hodges B, Byrne PN. World conference on medical education: a window on the globalizing world of medical education? Med Teach. 2007;29(2-3): e63-e66. doi:10.1080/01421590601175291.

20. Wilbur K, Paiva M, Black EK. Pharmacy Student and preceptor impressions of faculty liaison visits to experiential training sites. Am J Pharm Educ. 2015;79: 134. doi:10.5688/ajpe799134.

21. Henderson D, McGrath PD, Patton MA. Experience of clinical supervisors of international medical graduates in an Australian district hospital. Aust Health Rev. 2017;41(4):365-371. doi:10.1071/AH15094.

22. Govaerts MJ, Van de Wiel MW, Schuwirth LW, Van der Vleuten CP, Muijtjens AM. Workplace-based assessment: raters' performance theories and constructs. Adv Health Sci Educ. 2013;18(3):375-396. doi: 10.1007/s10459-012-9376-x.

23. Gingerich A, Kogan J, Yeates P, Govaerts M, Holmboe E. Seeing the 'black box' differently: assessor cognition from three research perspectives. Med Educ. 2014;48(11):1055-1068. doi:10.1111/medu.12546. 
24. Gauthier G, St-Onge C, Tavares W. Rater cognition: review and integration of research findings. Med Educ. 2016;50(5):511-522. doi:10.1111/medu.12973.

25. Phillips D, Schweisfurth M. Comparative and International Education: An Introduction to Theory, Method and Practice. New York, NY: Continuum International Publishing; 2006.

26. Sun S. Organizational culture and its themes. Int $J$ Bus Manage. 2008;3:137-141. doi:10.5539/ijbm. v3n12p137.

27. Kozulin A. Vygotsky's Educational Theory in Cultural Context. Cambridge, UK: Cambridge University Press; 2003.

28. Trede F, Macklin R, Bridges D. Professional identity development: a review of the higher education literature. Stud High Educ. 2012;37(3):365-384. doi:10. 1080/03075079.2010.521237.

29. Schein EH. Organizational culture. Am Psychol. 1990; 45(2):109-119. doi:10.1037/0003-066X.45.2.109.

30. The Canadian Council for Accreditation of Pharmacy Programs. Accreditation Standards for the First Professional Degree in Pharmacy Programs. Toronto, ON; 2014:1-29.

31. Association of Faculties of Pharmacy in Canada (AFPC). Educational Outcomes for First Professional Degree Programs in Pharmacy in Canada 2017. Ottawa, ON; 2017.

32. Hofstede G. Culture's Consequences: Comparing Values, Behaviors, Institutions, and Organizations across Nations. 2nd ed. Thousand Oaks, CA: Sage Publications; 2001.

33. Wilby KJ, Govaerts MJ, Austin Z, Dolmans DH. Exploring the influence of cultural orientations on assessment of communication behaviours during patient-practitioner interactions. BMC Med Educ. 2017;17(1):61. doi:10.1186/s12909-017-0899-y.

34. Verma A, Griffin A, Dacre J, Elder A. Exploring cultural and linguistic influences on clinical communication skills: a qualitative study of international medical graduates. BMC Med Educ. 2016;16(1):162.

35. Meeuwesen L, van den Brink-Muinen A, Hofstede G. Can dimensions of national culture predict crossnational differences in medical communication? Patient Educ Couns. 2009;75(1):58-66. doi:10.1016/j. pec.2008.09.015.

36. Deschepper R, Grigoryan L, Lundborg CS, et al. Are cultural dimensions relevant for explaining crossnational differences in antibiotic use in Europe? BMC Health Serv Res. 2008;8(1):123. doi:10.1186/14726963-8-123.

37. Regehr G, Ginsburg S, Herold J, Hatala R, Eva K, Oulanova O. Using "standardized narratives" to explore new ways to represent faculty opinions of resident performance. Acad Med. 2012;87(4):419-427. doi:10.1097/ACM.0b013e31824858a9.

38. Rawlings A, Knox AD, Park YS, et al. Development and evaluation of standardized narrative cases depicting the general surgery professionalism milestones. Acad Med. 2015;90(8):1109-1115. doi:10.1097/ACM. 0000000000000739 .
39. Alexander CS, Becker HJ. The use of vignettes in survey research. Pub Opin Q. 1978;42(1):93-104. doi:10. $1086 / 268432$

40. Wilbur K, Hassaballa N, Mahmood OS, Black EK. Describing student performance: a comparison among clinical preceptors across cultural contexts. Med Educ. 2017;51(4):411-422. doi:10.1111/medu.13223.

41. Clayton MJ. Delphi: a technique to harness expert opinion for critical decision-making tasks in education. Educ Psychol.1997;17(4):373-386. doi:10.1080/ 0144341970170401.

42. Powell C. The Delphi technique: myths and realities. $J$ Adv Nurs. 2003;41(4):376-382.

43. Braun V, Clarke V. Using thematic analysis in psychology. Qual Res Psychol. 2006;3(2):77-101. doi:10. 1191/1478088706qp063oa.

44. Kheir N, Zaidan M, Younes H, El Hajj M, Wilbur K, Jewesson PJ. Pharmacy education and practice in 13 Middle Eastern countries. Am J Pharm Educ. 2008; 72(6):133. doi:10.5688/aj7206133.

45. Donald M, King-Shier K, Tsuyuki RT, et al. Patient, family physician and community pharmacist perspectives on expanded pharmacy scope of practice: a qualitative study. CMAJ Open. 2017;5(1):E205-E212. doi:10.9778/cmajo.20160135.

46. Lave J, Wenger E. Situated Learning: Legitimate Peripheral Participation. Cambridge, UK: Cambridge University Press; 1991.

47. Wilby KJ, Black EK, Austin Z, Mukhalalati B, Aboulsoud S, Khalifa SI. Objective structured clinical examination for pharmacy students in Qatar: cultural and contextual barriers to assessment. East Mediterr Health J. 2016;22(4):251-257. doi:10.26719/2016.22.4. 251.

48. Paravattil B, El Sakrmy N, Shaar S. Assessing the evidence based medicine educational needs of community pharmacy preceptors within an experiential program in Qatar. Curr Pharm Teach Learn. 2018; 10(1):47-53. doi:10.1016/j.cptl.2017.09.005.

49. Yardley S, Teunissen PW, Dornan T. Experiential learning: AMEE guide No. 63. Med Teach. 2012;34(2): e102-e115. doi:10.3109/0142159X.2012.650741.

50. Strand P, Edgren G, Borna P, Lindgren S, Wichmann-Hansen G, Stalmeijer RE. Conceptions of how a learning or teaching curriculum, workplace culture and agency of individuals shape medical student learning and supervisory practices in the clinical workplace. Adv Health Sci Educ Theory Pract. 2015; 20(2):531-557. doi:10.1007/s10459-014-9546-0.

51. Kheir N, Al Saad D, Al Naimi S. Pharmaceutical care in the Arabic-speaking Middle East: literature review and country informant feedback. Avicenna. 2013;1:2. doi:10.5339/avi.2013.2.

52. Kane T. Higher education in Qatar: does a US medical school break the baroque arsenal. In: Donn G, Al Manthri Y, eds. Education in the Broader Middle East: Borrowing a Baroque Arsenal. Oxford, UK: Oxford Symposium Books, 2013:85-105.

53. Ginsburg S, McIlroy J, Oulanova O, Eva K, Regehr G. Toward authentic clinical evaluation: pitfalls in the pursuit of competency. Acad Med. 2010;85(5): 780-786. doi:10.1097/ACM.0b013e3181d73fb6. 
54. Bogo M, Regehr C, Woodford M, Hughes J, Power R, Regehr G. Beyond competencies: field instructors' descriptions of student performance. J Soc Work Educ. 2006;42(3):579-594. doi:10.5175/JSWE.2006.200404145.

55. Bogo M, Regehr C, Power R, Hughes J, Woodford M, Regehr G. Toward new approaches for evaluating student field performance: tapping the implicit criteria used by experienced field instructors. J Soc Work Educ. 2004;40(3):417-426. doi:10.1080/10437797.2004. 10672297.

56. Ginsburg S, van der Vleuten CPM, Eva KW. The hidden value of narrative comments for assessment: a quantitative reliability analysis of qualitative data. Acad Med. 2017;92(11):1617-1621. doi:10.1097/ACM. 0000000000001669.

57. Signorini P, Wiesemes R, Murphy R. Developing alternative frameworks for exploring intercultural learning: a critique of Hofstede's cultural difference model. Teach High Educ. 2009;14(3):253-264.
58. McSweeney B. Hofstede's model of national cultural differences and their consequences: a triumph of faith-a failure of analysis. Hum Relat. 2002;55(1): 89-118. doi:10.1177/0018726702551004.

59. Jones M. Hofstede-culturally questionable? Paper presented at: Oxford Business \& Economics Conference, June 24-26, 2007; Oxford, UK.

60. Magnusson P, Wilson RT, Zdravkovic S, Xin Zhou J, Westjohn SA. Breaking through the cultural clutter: a comparative assessment of multiple cultural and institutional frameworks. Int Market Rev. 2008;25(2): 183-201. doi:10.1108/02651330810866272.

61. Hofstede G. Dimensions do not exist: a reply to Brendan McSweeney. Hum Relat 2002;55(11):1355-1361.

62. Hodges BD, Maniate JM, Martimianakis MA, Alsuwaidan M, Segouin C. Cracks and crevices: globalization discourse and medical education. Med Teach. 2009;31(10):910-917. doi:10.3109/01421590802534932. 